\title{
Effect of Web-Based Training on Complication Control and Quality of Life of Spinal Cord Damaged Individuals: Randomized Controlled Trial
}

\author{
Elif Ateş ${ }^{1} \mathbb{D}$, Naile Bilgili² \\ ${ }^{1}$ Department of Nursing, Faculty of Health Sciences, Acıbadem University, Istanbul, Turkey \\ ${ }^{2}$ Department of Nursing, Faculty of Health Sciences, Gazi University, Ankara, Turkey \\ Correspondence Author: Elif Ateş \\ E-mail: Elif.ates@acibadem.edu.tr, elifates83@gmail.com
}

Received: 23.03 .2020

Accepted: 30.05 .2021

\begin{abstract}
Objective: This study was conducted to determine the effect of web-based training on complication control and quality of life of spinal cordinjured patients.

Methods: A pre-test-post-test, experimental study including a control group. A total of 62 men participated from two different physical therapy and rehabilitation hospitals. The training, monitoring, and data collection steps were provided via a webpage (www.omurgahemsirelikegitim. com) and telephone.

Results: It was determined that there was a statistically significant difference between the experimental and control groups regarding the complications related to respiration, circulation, gastrointestinal, urinary, and musculoskeletal systems. Regarding the complications related to sexual life, comparing experimental and control groups the pre and post evaluations, detected an increase in difficulty in sexual life after the injury both experimental and control groups. There was no statistically significant difference between the two groups in terms of quality of life scale subscale scores.

Conclusion: These results show that telephone monitoring plus web-based training is effective in controlling disease complications in patients with spinal cord injury. However, to improve the quality of life, it is important to establish interventions involving individuals and families, and physical, social and mental health services.
\end{abstract}

Keywords: Education, spinal cord injuries, nursing, quality of life, home care services

\section{INTRODUCTION}

Spinal Cord Injury (SCl) is an important health problem that causes lifestyle changes resulting in biophysical, psychological, social, and economic dependence. After the injury, individuals might have to cope with secondary, long-term complications caused by the disease. According to a study by Van Loo and colleagues, almost half of the secondary complications, particularly in the acute phase, can be prevented after injury (urinary tract infection-UTI, constipation, etc.) (1). Therefore, it is of most importance to prevent secondary complications and to increase the quality of life of individuals. This can be done by educating and monitoring these injured individuals (2).

Although spinal cord-injured patients (SCIPs) are informed about secondary complications in the hospital setting, this information is often insufficient, or the patients cannot cope with the complications when in the home environment. To resolve these complications, spinal cord-injured patients either visit the hospital (in case of emergency) (3-5) or search the internet for information because of health problems. Because of the frequent use of the internet by SCIPs (6) and the problems their disabilities can cause when visiting health clinics. It is appropriate to use web-based training methods for these patients.

In this study, we aimed to determine the effect of a webbased training program on the quality of life and complication control in SCIPs.

\section{METHODS}

\subsection{Study Design}

This was a pre-test-post-test experimental study with a control group. Physical therapy and rehabilitation hospitals ( 2 large hospitals in 2 different cities in total) have been 
carried out through the webpage with individuals who were in the process of being discharged

\subsection{Participants}

Participation criteria included having been diagnosed with paraplegia, literacy, having computer access, having internet access, being between 18 - and 45-years-old, being open to communication and cooperation, and having been a maximum of 1 year since the diagnosis of the injury. Following a power analysis, 62 male individuals were sampled with $88 \%$ power, 31 in each group. 108 individuals were interviewed until this sample was reached (Figure 1: Research flow chart). Simple randomization and coin flip method is used.

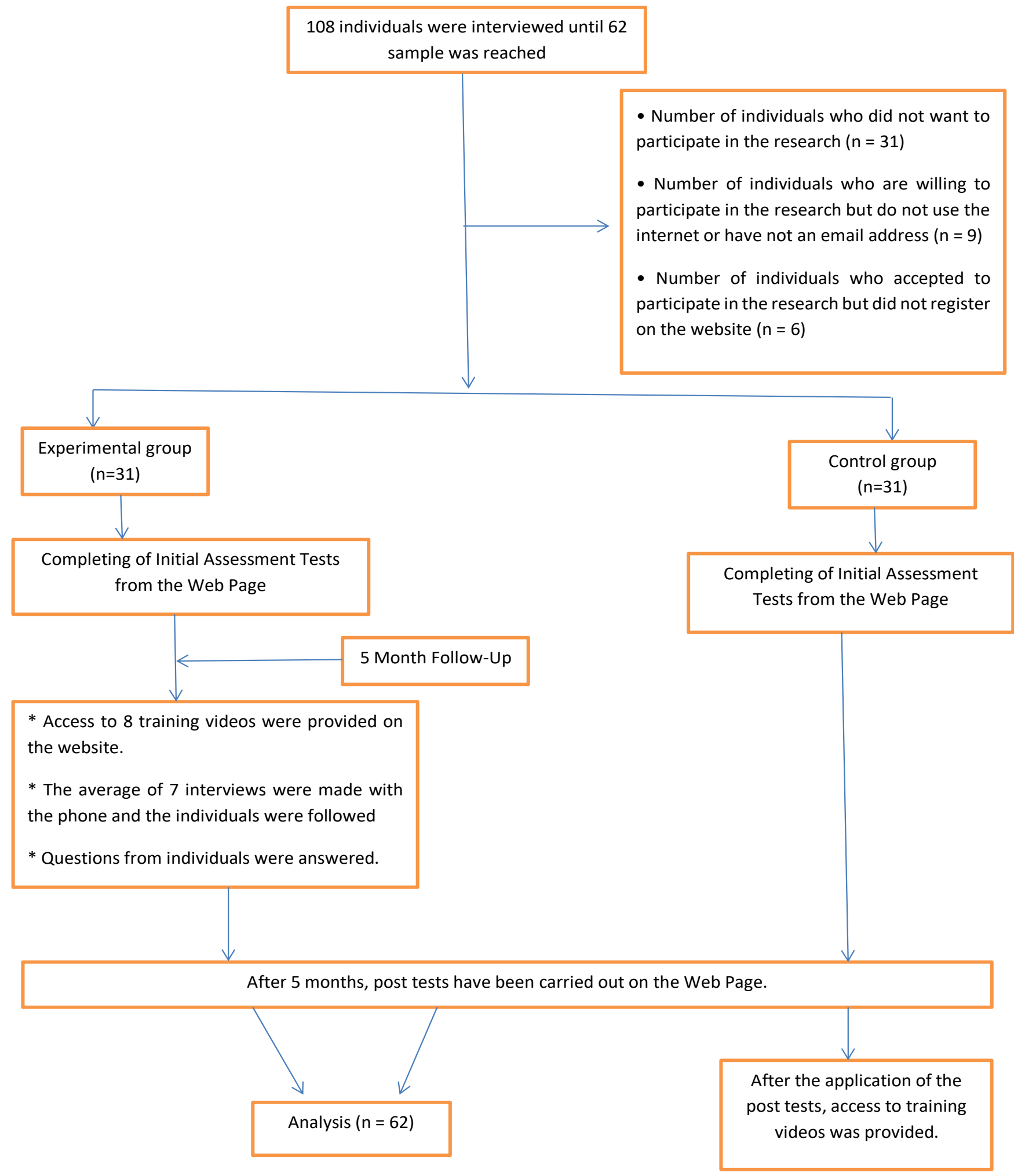

Figure 1: Research flow chart 


\subsection{Website Preparation Process}

The contents of the training videos included on the webpage were prepared by interviewing researchers and three specialist faculty members, as well as performing a literature review ${ }^{1,2}$. The titles of the eight training videos were: General information about spinal cord injury (Training video \#1, average 8 minute), Breathing, breathing exercise, assisted cough, postural drainage, (Training video \#2, average 18 minute), Circulation (Training video \#3, average 24 minute), Gastrointestinal, and enema application (Training video \#4, average 20 minute), Urinary, clean intermittent catheterization (CIT) application, (Training video \#5, average 20 minute), Musculoskeletal system problems after spinal cord injury, positioning, active and passive exercises, (Training video \#6, average 18 minute), Safety tips and solutions, pressure sores (Training video \#7, average 12 minute), and Sexuality (Training video \#8, average 12 minute). The training videos were recorded Center for Advanced Simulation and Education Simulation Laboratory. The training videos were edited and uploaded to the webpage by a specialist.

The webpage included training videos and questionnaires. The webpage was posted to the www.omurgahemsirelikegitim. com website. Users could access the prepared training videos through their membership account, which they qualified for by completing the prepared surveys. The control group was prevented from completing the questionnaires, and the software did not allow them to access the videos without completing the post-tests or within 5 months of the registration date.

\subsection{Interventions}

The study data were collected by the researcher for 11 months, beginning on 1 January 2017 and continuing until reaching 62 participants and the 5-month follow-up period was achieved. Implementation steps were:

- After the preparation of the webpage, five SCIPs (these individuals were excluded from the sample) were introduced to the webpage for preliminary evaluation, and any missing aspects were eliminated.

- Preliminary interviews were conducted with those individuals who were diagnosed with paraplegia and scheduled to be discharged from the hospital, where information was given about the purpose and method of the investigation.

- For the individuals who agreed to participate in the research, they were instructed how to view the webpage on a computer or mobile phone.

- After completing the pre-tests, the experimental group gained immediate access to the training videos, whereas the control group gained access to this content 5 months after completing the pre-tests and post - tests.
- Once at 20 days an average of seven regular telephone (lasting an average of 13 minutes) interviews were conducted with the experimental group, where they were asked how much time they spent watching the training videos. Phone tracking guide content is in the form of talking about videos to watch. Some individuals made phone calls more frequently. Because when the individuals meet any problem, they call directly researcher. We talked about the solution proposal for the problem and these individuals were monitored with phone more frequently.

- There was no communication with the control group during these 5 months. Since the participants were given this information, the participants did not call the researcher.

- After 5 months, the individuals in both groups were reminded about completing the post-tests.

\subsection{Ethical Considerations}

Ethical approval was obtained from the GMMA (Gulhane Military Medical Academy) ethical committee (registration number: 508/Date:15.12.2015). Also, all the participants were informed about the study and written informed consent was obtained from the participants volunteering to participate in the study.

\subsection{Measures from the Questionnaire Data}

As part of the pre-tests, via the webpage, participants completed three questionnaires: an individual's data collection form, a form addressing the complications/ problems of the participants, and a short form of the World Health Organization (WHO) quality of life scale. In the posttest; the participants repeated the complications/problems and WHO quality of life questionnaires.

\subsubsection{Individual's data collection form}

This form consisted of 18 questions about the participant's socio-demographic background and disease history.

\subsubsection{Form addressing the complications/problems}

This form included questions such as the number of complications, the complications due to $\mathrm{SCl}$, what complications developed related to the system, what kind of intervention is done for the developing complication, how do you evaluate your diet, how much fluid is taken daily, how do you pass urine, how do you empty your bowels, and are you having a problem with your bedside shift. It was developed by researchers in line with the literature (1). 


\subsubsection{World health organization quality of life scale-short form}

This scale evaluates how an individual perceives his or her quality of life. The validity and reliability studies for this form in Turkey were conducted by Eser et al. (1999). The WHO short form of the quality of life scale (WHOQOL-BREF-TR) consists of 26 questions divided into four parts: physical, mental, environmental, and social. During the Turkish validity studies, a question was added to the questionnaire, so that the total number of questions became 27 . The scale has Likert type scores ranging from 1 to 5 . As scores from the subscales of the scale increase, the quality of life increases. The Cronbach Alpha values calculated for examining the self-consistency of the Turkish form of the scale were found to be 0.83 in the physical field, 0.66 in the spiritual field, 0.53 in the social field, 0.73 in the environmental field. The Pearson coefficients, calculated for each question to examine the test-retest reliability, vary between 0.57 and $0.81(7,8)$.

\subsection{StatisticalAnalyses}

All statistical analyses were performed by SPSS 22 software (IBM Corp. Released 2013. IBM SPSS Statistics for Windows, Version 22.0. Armonk, NY: IBM Corp.). The normality of data was evaluated using the Shapiro Wilks test. Analyses included descriptive statistical methods (mean, standard deviation, frequency), as well as t-tests (normally distributed quantitative data) and Mann Whitney $U$ tests (for not normally distributed quantitative data). In the evaluation of the pre and post test data showing normal distribution, t-tests were used when comparing dependent groups, and Wilcoxon Marked Rank test was used for those data that did not show a normal distribution. The Chi-Square test, Continuity (Yates) correction, and Fisher's exact Chi-square test were used in the evaluation of qualitative data, and the McNemar Bowker test was used in the evaluation of qualitative data of the pre and post tests. The confidence interval was estimated to be $95 \%(p<0.05)$.

\subsection{Hypotheses}

$\mathrm{H} 1$ : There is no difference between the incidence of complications in individuals with and without web-based training.

$\mathrm{H} 2$ : There is no difference between the quality of life scores of individuals with and without web-based education.

\section{RESULTS}

There were no statistically significant differences between the experimental and control groups in terms of age, marital status, educational status, work status, economic status, and individual characteristics of the patients $(p>0.05)$. This indicates that the groups are homogeneously distributed.

\subsection{Findings Related to the Use of a Training Webpage by} SCIPs

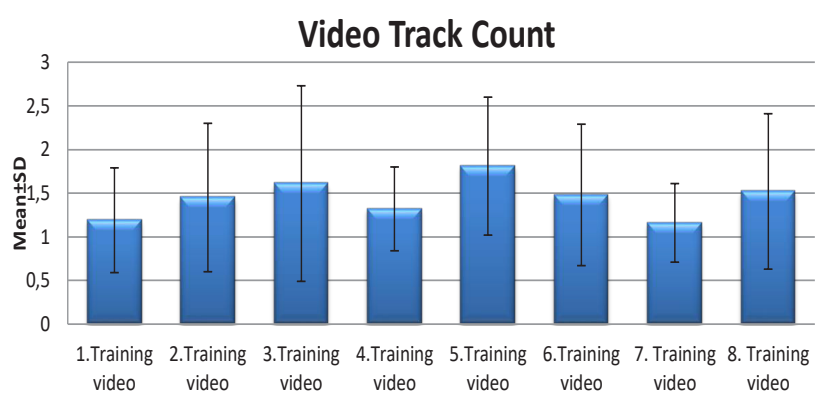

Figure 2. Experiment Group Video Count.

Among the videos, the video addressing urinary system problems was watched more than the others.

\subsection{Findings Related to Complications/Problems of SCIPS}

In the first evaluation of the experimental and control groups, the most common complications were UTI $(80.6 \%)$, spasticity $(69.4 \%)$, constipation $(64.5 \%)$, related problems sexuality (56.5\%), and orthostatic hypotension (35.5\%).

\subsection{Findings Related to Complications/Problems of the Systems}

When comparing the two groups, we detected a difference in favor of the experimental group in case of sputum from respiratory system complications $\left(\chi^{2}=5.797 ; p<0.05\right)$ (Table 1). For the complications of the circulatory system, thermoregulation impairment $\left(\chi^{2}=5.063 ; p<0.05\right)$ and orthostatic hypotension $\left(\chi^{2}=6.229 ; p<0.05\right)$ were less frequent in the experimental group than the control group $(p<0.05)$. There were no significant differences between the groups for the gastrointestinal system complications (indigestion and heartburn) ( $p>0.05)$. However, at the posttest, the experimental groups had a significantly greater decrease in the rate of constipation than the control groups $\left(\chi^{2}=8.015 ; p<0.01\right)$. In the pre - and post-test evaluation of the urinary system complications, there was no statistically significant difference between the two groups in terms of urinary tract infection (UTI) $(p>0.05)$; however, for the experimental group, there was a significant decrease in UTIs when comparing the pre-and post-test evaluations ( $p<0.05)$. Among the musculoskeletal complications, only falls was statistically different between the groups $\left(\chi^{2}=5.365 ; p<0.05\right)$. Regarding the complications related to sexual life, comparing the pre and post evaluations, we detected an increase in difficulty in sexual life after the injury $(p<0.05)$ and problems in sexual intercourse $(p<0.01)$ for both the experimental and control groups.

The H1 hypothesis was rejected. 
Table 1. Distribution of Problems Experienced by the Experimental and Control Groups in the Pre-and Post-Test Systems

\begin{tabular}{|c|c|c|c|c|c|c|c|c|}
\hline & & & $\begin{array}{l}\text { Experimental } \\
\text { Groups }\end{array}$ & & Control Groups & & & \\
\hline \multirow{13}{*}{$\begin{array}{l}\text { Respiratory System } \\
\text { Complications }\end{array}$} & & & $\begin{array}{l}\text { Total number of } \\
\text { complications }\end{array}$ & $\begin{array}{c}\mathrm{n}(31) \\
(\%)\end{array}$ & $\begin{array}{c}\text { Total number of } \\
\text { complications }\end{array}$ & $\begin{array}{c}\mathrm{n}(31) \\
(\%)\end{array}$ & $x^{2}$ & $\mathrm{p}$ \\
\hline & \multirow{3}{*}{$\begin{array}{l}\text { Problems with } \\
\text { respiratory system }\end{array}$} & Pre-Test & 7 & 22.6 & 11 & 35.5 & 0.705 & .401 \\
\hline & & Post- Test & 5 & 16.1 & 10 & 32.3 & 1.407 & .236 \\
\hline & & $2 p$ & .687 & & .10 & & & \\
\hline & \multirow{3}{*}{ Distress breathing } & Pre-Test & 3 & 9.7 & 6 & 19.4 & 0.52 & .471 \\
\hline & & Post- Test & 1 & 3.2 & 3 & 9.7 & 0.267 & .605 \\
\hline & & $2 p$ & .625 & & .37 & & & \\
\hline & \multirow[t]{3}{*}{ Inability to cough } & Pre-Test & 4 & 12.9 & 9 & 29 & 1.557 & .212 \\
\hline & & Post- Test & 3 & 9.7 & 9 & 29 & 2.583 & .108 \\
\hline & & $2 p$ & 1 & & 1 & & & \\
\hline & \multirow[t]{3}{*}{ Sputum } & Pre-Test & 2 & 6.5 & 5 & 16.1 & 0.644 & .422 \\
\hline & & Post- Test & 0 & 0.0 & 7 & 22.6 & 5.797 & $.016 *$ \\
\hline & & $2 p$ & - & & .687 & & & \\
\hline \multirow{13}{*}{$\begin{array}{l}\text { Circulatory System } \\
\text { Complications }\end{array}$} & \multirow[t]{4}{*}{ Edema } & Pre- Test & 12 & 38.7 & 14 & 45.2 & 0.066 & .797 \\
\hline & & Post- Test & 6 & 19.4 & 13 & 41.9 & & \\
\hline & & $2 p$ & & & & & 2.732 & .098 \\
\hline & & & .109 & & .100 & & & \\
\hline & \multirow{3}{*}{$\begin{array}{l}\text { Thermoregulation } \\
\text { impairment }\end{array}$} & Pre-Test & 10 & 32.3 & 15 & 48.4 & 1.072 & .300 \\
\hline & & Post- Test & 2 & 6.5 & 10 & 32.3 & 5.063 & $.024 *$ \\
\hline & & $2 p$ & $.039^{\prime}$ & & .227 & & & \\
\hline & \multirow[t]{3}{*}{ Orthostatic hypotension } & Pre-Test & 28 & 90.3 & 30 & 96.8 & 0.267 & .605 \\
\hline & & Post- Test & 2 & 6.5 & 11 & 35.5 & 6.229 & $.013 *$ \\
\hline & & $2 p$ & .004 & & .063 & & & \\
\hline & \multirow[t]{3}{*}{ Autonomic dysreflexia } & Pre-Test & 8 & 25.8 & 12 & 38.7 & 0.664 & .415 \\
\hline & & Post- Test & 4 & 12.9 & 10 & 32.3 & 2.307 & .129 \\
\hline & & $2 p$ & .219 & & .625 & & & \\
\hline \multirow{9}{*}{$\begin{array}{l}\text { Gastrointestinal System } \\
\text { Complications }\end{array}$} & \multirow[t]{3}{*}{ Indigestion } & Pre-Test & 6 & 19.4 & 6 & 19.4 & 0.001 & .100 \\
\hline & & Post- Test & 2 & 6.5 & 7 & 22.6 & 2.08 & .149 \\
\hline & & $2 p$ & .219 & & .100 & & & \\
\hline & \multirow[t]{3}{*}{ Heartburn } & Pre-Test & 5 & 16.1 & 4 & 12.9 & 0.001 & .100 \\
\hline & & Post- Test & 3 & 9.7 & 4 & 12.9 & 2.08 & .149 \\
\hline & & $2 p$ & .500 & & .100 & & & \\
\hline & \multirow[t]{3}{*}{ Constipation } & Pre-Test & 17 & 54.8 & 23 & 74.2 & 1.761 & .184 \\
\hline & & Post- Test & 7 & 22.6 & 19 & 61.3 & 8.015 & $.005^{* *}$ \\
\hline & & $2 p$ & .013 & & .45 & & & \\
\hline \multirow{3}{*}{$\begin{array}{l}\text { Urinary System } \\
\text { Complications }\end{array}$} & \multirow[t]{3}{*}{ Urinary tract infection } & Pre-Test & 24 & 77.4 & 26 & 83.9 & 0.103 & .520 \\
\hline & & Post- Test & 15 & 48.4 & 18 & 58.1 & 0.259 & .611 \\
\hline & & $2 p$ & .035 & & .077 & & & \\
\hline \multirow{9}{*}{$\begin{array}{l}\text { Musculoskeletal } \\
\text { Complications }\end{array}$} & \multirow[t]{3}{*}{ Spasticity } & Pre-Test & 20 & 64.5 & 23 & 74.2 & 0.304 & .582 \\
\hline & & Post- Test & 19 & 61.3 & 19 & 61.3 & 0.001 & .100 \\
\hline & & $2 p$ & 1 & & .42 & & & \\
\hline & Heterotopic ossification & Pre-Test & 7 & 22.6 & 6 & 19.4 & 0.001 & .100 \\
\hline & & Post- Test & 3 & 9.7 & 3 & 9.7 & 0.001 & .100 \\
\hline & & $2 p$ & .219 & & .508 & & & \\
\hline & Fall & Pre-Test & 17 & 54.8 & 13 & 41.9 & 0.581 & .446 \\
\hline & & Post- Test & 8 & 25.8 & 18 & 58.1 & 5.365 & $.021 *$ \\
\hline & & $2 p$ & $.035^{\prime}$ & & .267 & & & \\
\hline Complications Related & Having difficulty in sexual & Pre-Test & 23 & 74.2 & 23 & 74.2 & 0.001 & .100 \\
\hline To Sexual Life & life after injury & Post- Test & 29 & 93.5 & 30 & 96.8 & 0.001 & .100 \\
\hline & & $2 p$ & .031 & & .016 & & & \\
\hline & Problems during sexual & Pre-Test & 18 & 58.1 & 18 & 58.1 & 0.001 & .100 \\
\hline & intercourse / activity & Post- Test & 26 & 83.9 & 27 & 87.1 & 0.001 & .100 \\
\hline & & $2 p$ & .008 & & .012 & & & \\
\hline
\end{tabular}

${ }^{1}$ Continuity (Yates) Correction and Fisher's Exact Test, ${ }^{2}$ McNemar Bowker Test, ${ }^{*} p<.05,{ }^{* *} p<.01$ 


\subsection{Findings related to the quality of life of SCIPs}

Table 2. The Pre and Post Assessment of WHOQOL-BREF-TR Scores

\begin{tabular}{|c|c|c|c|c|c|}
\hline $\begin{array}{l}\text { WHOQOL- } \\
\text { BREF-TR } \\
\text { Subdomains }\end{array}$ & & $\begin{array}{l}\text { Experimental Groups } \\
(n=31) \text { Mean } \pm S D\end{array}$ & $\begin{array}{c}\text { Control Groups }(n=31) \\
\text { Mean } \pm S D\end{array}$ & ${ }^{1} t$ & $p$ \\
\hline \multirow[t]{5}{*}{ Physical domain } & Pre-Test & $20.52 \pm 3.91$ & $19.45 \pm 4.42$ & 1.005 & 0.319 \\
\hline & Post-Test & $21.06 \pm 4.01$ & $21.06 \pm 3.92$ & 0.000 & 0.100 \\
\hline & Difference & $0.55 \pm 3.39$ & $1.61 \pm 2.82$ & -1.342 & 0.185 \\
\hline & ${ }^{2} \mathrm{t}$ & -0.899 & -3.179 & & \\
\hline & $p$ & .376 & $.003 * *$ & & \\
\hline \multirow[t]{5}{*}{ Spiritual domain } & Pre-Test & $21.10 \pm 4.13$ & $19.13 \pm 4.19$ & 1.861 & 0.068 \\
\hline & Post-Test & $19.77 \pm 3.55$ & $19.26 \pm 3.61$ & 0.568 & 0.572 \\
\hline & Difference & $-1.32 \pm 3.94$ & $0.13 \pm 2.86$ & -1.661 & 0.102 \\
\hline & ${ }^{2} \mathrm{t}$ & 1.871 & -0.251 & & \\
\hline & $p$ & .071 & .803 & & \\
\hline \multirow[t]{5}{*}{ Social domain } & Pre-Test & $9.26 \pm 3.13$ & $8.13 \pm 3.27$ & 1.388 & 0.170 \\
\hline & Post-Test & $9.35 \pm 2.70$ & $8.45 \pm 2.58$ & 1.346 & 0.183 \\
\hline & Difference & $0.10 \pm 2.23$ & $0.32 \pm 2.44$ & -0.381 & 0.705 \\
\hline & ${ }^{2} \mathrm{t}$ & -0.242 & -0.736 & & \\
\hline & $p$ & .810 & .468 & & \\
\hline \multirow[t]{5}{*}{ Environmental domain } & Pre-Test & $23.84 \pm 6.94$ & $23.42 \pm 7.04$ & 0.236 & 0.814 \\
\hline & Post-Test & $25.90 \pm 5.95$ & $25.16 \pm 5.69$ & 0.502 & 0.618 \\
\hline & Difference & $2.06 \pm 3.90$ & $1.74 \pm 4.30$ & 0.309 & 0.758 \\
\hline & ${ }^{2} \mathrm{t}$ & -2.949 & -2.253 & & \\
\hline & $p$ & $.006 * *$ & $.032 *$ & & \\
\hline
\end{tabular}

${ }^{1}$ Student $t$-Test ${ }^{2}$ Paired Sample t-Test ${ }^{*} p<.05{ }^{*} p<.01$

WHOQOL-BREF-TR total scores of the experimental and control groups were similar $(p>0.05)$ (Table 2). In the experimental group, the average score of the environmental domain subscale in the post-test was significantly higher than the average score of the pre-test $\left({ }^{2} t=-2.949 ; p>0.01\right)$. In the control group, the difference between the mean scores of the physical domain and the environmental domain subscale was statistically significant $\left({ }^{2} \mathrm{t}=-3.179 ; p=0.010 ;{ }^{2} \mathrm{t}=-2.253\right.$; $p>0.05)$.

The $\mathrm{H} 2$ hypothesis was rejected.

\section{DISCUSSION}

This study demonstrates that telephone monitoring together with web-based training is effective in controlling the complications of SCIP. SCIPs who participated in the study watched the training videos, especially the video related to UTIs, which are frequent among SCIPs (Fig. 1). We found that SCIPs prefer to contact the researcher directly by telephone rather than actively using the webpage. Because the participants in the study directly called the researcher when they had a problem. Afterwards, the individuals were directed to the training videos on the web page by the researcher. This emphasizes the importance of individual counseling, as well as standard web practice and the importance of nurse follow-up programs.

All almost of SCIPs, at least one complication arised as a result of physical changes due to the injury was serious enough to require health care services. ${ }^{2}$ The most frequent complications among the SCIPs participating in this study were UTI, spasticity, constipation, sexually related problems, and orthostatic hypotension, which is in line with the literatüre (4,5,9-11).

The proposed contents for the training videos included increasing fluid intake, breathing exercises, postural drainage, healthy nutrition, positioning, hygiene, the points to be considered in clean intermittent catheterization application, main points in bowel training, and active and passive exercises to prevent complications. Also, suggestions were made about the applications that should be done when the complication develops. In our study, it was determined that thermoregulation impairment, orthostatic hypotension, the prevalence of sputum, UTI, and constipation rates of the SCIPS in the experimental group decreased. In these results of the study, besides the web-based training given, it is thought that interviews about complications with SCIPs on the telephone are effective. However, in the literature, the reported causes of thermoregulation defects after injury are infection status and decreased or increased ambient temperature. ${ }^{12}$ Also, increased daily fluid (2-2.5 I) and salt intake ( $\geq 8 \mathrm{~g} / \mathrm{d}$ ), pressure socks, and avoiding sudden position changes and heat have been recommended for the treatment of orthostatic hypotension (instead of pharmacological treatments)..$^{13}$ In the literature, it is indicated that non-pharmacological methods are effective in bowel management, which supports the results of our study. (4-16). It is thought that the preventive 
and supportive approaches in the training videos and the close monitoring of the individuals who are followed by the telephone are thought to be the reason for the decrease in the incidence of these complications in this study.

The fall rates observed in the experimental group were also reduced. Most of the falling events were due to loss of balance when attempting to walk. In one study, $43.0 \%$ of falls of SCIPs occurred within the home, and $76.0 \%$ of individuals were walking during the fall (17). The falls of SCIPs are caused by loss of balance, lower extremity muscle weakness, and environmental hazards.

Sexuality is not a topic that is easily spoken about with SCIPs (18). Sexuality is not integrated into the rehabilitation process, and can even be ignored. However, SCIPs are known to need training and counseling on sexuality (19). Similarly, in this study, the individuals who were followed-up, especially those that were single, asked questions about sexuality, and they expressed their need for information on this subject. The most common sexuality topics the participants wanted to talk about were problems related to erection/ejaculation, sexual intercourse, and reproduction. In one study, the subjects discussed sexuality, including relationships, sexual preferences, their partner, gender, the adaptation process, culture, and religion (19). In general, the sexual issues discussed vary according to the culture. It is thoughtthat the increased incidence of problems in sexual life is because the individuals who participate in this study are composed of a young population; for them, sexuality is associated with sexual intercourse and erection/ejaculation, which some do not want to discuss.

In the literature, the quality of life of SCIPs is reported to be lower than that of healthy individuals (20). There was no statistically significant difference in the quality of life total scale scores between the two groups in our study. However the environmental subscale scores of both groups and the physical subscale of the control group were statistically significant. The study participants had an average time since injury of 6 months. Mostly, SCIPs are in the process of adapting to a new life, new bodies, and new environmental conditions. In this period, individuals face physical difficulties. Moreover, based on the literature, the factors affecting the quality of life of SCIPs vary.

The quality of life of SCIPs can be influenced by physical difficulties, psychological and socioeconomic problems, and difficulties in returning to work or education (21). In some studies, the quality of life of the individuals was independently associated with secondary complications (e.g.m musculoskeletal pain, pressure scar, problematic spasticity, constipation) (22). Also, many factors influence the quality of life, such as perceived health status, subjective health, the perception of health, satisfaction, mindset, psychiatric status, and well-being (23). Recent research has found that the effect of psychosocial issues is important for quality of life, including social integration, social relations, self-efficacy, self-esteem, view of life, leisure time, and consistent emotional state (24).
Apart from disease complications and individual psychosocial states, environmental and physical obstacles also affect quality of life. Almost half (48.3\%) of SCIPs reported physical obstacles related to the home environment, such as lack of lifts and ramps and inadequate space for a wheelchair to move (25). Most (79.8\%) SCIPs have between 3 and 7 rooms, $12.6 \%$ have between $8-10$, and there are no private rooms for the individual (25). Most (75.6\%) SCIPs experience transport problems, including irregular sidewalks, special public transport for disabled people, special ramps for wheelchair users, and an absence of private parking spaces for disabled people (25).

In brief the quality of life, in general, can be affected by limitations in physical functions, as well as social life participation, environmental barriers, individual personality characteristics, individual demographic characteristics, and health perceptions. That is, the quality of life can vary depending on the person. According to the results of the study, the frequency of complications has decreased, but longer-term interventions are required to increase the quality of life of individuals.

\section{CONCLUSION}

It has been determined that telephone monitoring together with web-based training is effective in controlling complications in SCIPs. Among the training videos, the video addressing the urinary system was watched the most. In complications of $\mathrm{SCl}$, such as constipation, orthostatic hypotension, and thermoregulation disorders, a decrease in favor of the experimental group was observed. There was no significant difference between the two groups in terms of the quality of life and sexual problems.

We propose that future studies should: monitor SCIPs by telephone and home visits (although web-based training can also be effective in the management of complications); research sexual counseling, and use broader samples of SCIPS when monitoring quality of life.

\section{Acknowledgements}

We thank individuals with spinal cord injury who participated in the study.

\section{REFERENCES}

[1] Van Loo MA, Post MWM, Bloemen JHA, Van Asbeck FWA. Care needs of persons with long-term spinal cord injury living at home in the Netherlands. Spinal Cord 2010;48(5):423-428.

[2] Ljungberg I, Kroll T, Libin A, Gordon S. Using peer mentoring for people with spinal cord injury to enhance self-efficacy beliefs and prevent medical complications. Journal of Clinical Nursing 2011;20(3-4):351-358.

[3] Krause JS, Reed KS, McArdle JJ. A Structural analysis of health outcomes after spinal cord injury. The Journal of Spinal Cord Medicine 2010;33(1):22-32. 
[4] Skelton F, Hoffman JM, Reyes M, Burns SP. Examining healthcare utilization in the first year following spinal cord injury. The Journal of Spinal Cord Medicine 2015;38(6):690-695.

[5] DeJong G, Tian W, Hsieh CH, Junn C, Karam C, Ballard PH, et al. Rehospitalization in the first year of traumatic spinal cord injury after discharge from medical rehabilitation. Archives of Physical Medicine and Rehabilitation 2013;94(4):87-97.

[6] Folan A, Barclay L, Cooper C, Robinson M. Exploring the experience of clients with tetraplegia utilizing assistive technology for computer access. Disability and Rehabilitation: Assistive Technology 2015;10(1):46-52.

[7] Eser SY, Fidaner H, Fidaner C, Elbi H, Eser E. Evaluation of quality of life WHOQOL-100 ve WHOQOL-BREF. 3P Journal 1999;7(2):5-13.

[8] Kavlu I, Pinar R. Effects of Job Satisfaction and Burnout on Quality of Life in Nurses Who Work in Emergency Services. Turkiye Klinikleri Journal of Medical Sciences 2009;29(6):15431555.

[9] Janssen TWJ, Prakken ES, Hendriks JMS, Lourens C, Van Der Vlist J, Smit CAJ. Electromechanical abdominal massage and colonic function in individuals with a spinal cord injury and chronic bowel problems. Spinal Cord 2014;52(9):693-696.

[10] Hetz SP, Latimer AE, Arbour-Nicitopoulos KP, Ginis KAM. Secondary complications and subjective well-being in individuals with chronic spinal cord injury: associations with self-reported adiposity. Spinal Cord 2011;49(2):266-272.

[11] Jaglal SB, Munce SEP, Guilcher SJ, Couris CM, Fung K, Craven BC, et al. Health system factors associated with rehospitalizations after traumatic spinal cord injury: a population-based study. Spinal Cord 2009;47(8):604-609.

[12] Karlsson AK, Krassioukov A, Alexander MS, Donovan W, Biering-Sørensen F. International spinal cord injury skin and thermoregulation function basic data set. Spinal Cord 2012;50(7):512-516.

[13] Currie KD, Krassioukov AV. A walking disaster: a case of incomplete spinal cord injury with symptomatic orthostatic hypotension. Clinical Autonomic Research 2015;25(5):335337.

[14] Krassioukov A, Eng JJ, Claxton G, Sakakibara BM, Shum S. Neurogenic bowel management after spinal cord injury: a systematic review of the evidence. Spinal Cord 2010;48(10):718-733.

[15] Coggrave M, Norton C, Wilson-Barnett J. Management of neurogenic bowel dysfunction in the community after spinal cord injury: a postal survey in the United Kingdom. Spinal Cord 2009;47(4):323-333.

[16] Forchheimer M, Meade MA, Tate D, Cameron AP, Rodriguez G, DiPonio L. Self-Report of Behaviors to Manage Neurogenic Bowel and Bladder by Individuals with Chronic Spinal Cord Injury: Frequency and Associated Outcomes. Topics in Spinal Cord İnjury Rehabilitation 2016;22(2):85-98.

[17] Phonthee S, Saengsuwan J, Siritaratiwat W, Amatachaya S. Incidence and factors associated with falls in independent ambulatory individuals with spinal cord injury: a 6-month prospective study. Physical Therapy 2013;93(8):1061-1072.

[18] Fronek P, Kendall M, Booth S, Eugarde E, Geraghty T. A longitudinal study of sexuality training for the interdisciplinary rehabilitation team. Sexuality and Disability 2011;29(2):87100.

[19] Alexander M, Courtois F, Elliott S, Tepper M. Improving Sexual Satisfaction in Persons with Spinal Cord Injuries: Collective Wisdom. Topics in Spinal Cord Injury Rehabilitation 2017;23(1):57-70.

[20] Arango-Lasprilla JC, Nicholls E, Olivera SL, Perdomo JL, Arango JA. Health-related quality of life in individuals with spinal cord injury in Colombia, South America. NeuroRehabilitation 2010;27(4):313-319.

[21] Parimbelli E, Pistarini C, Fizzotti G, Rognoni C, Olivieri G, Quaglini S. Computer-assessed preference-based quality of life in patients with spinal cord injury. BioMed Research International 2017;11.

[22] Adriaansen JJE, Ruijs LEM, van Koppenhagen CF, van Asbeck FWA, Snoek GJ, van Kuppevelt D, et al. Secondary health conditions and quality of life in persons living with spinal cord injury for at least ten years. Journal of Rehabilitation Medicine 2016;48(10):853-860.

[23] Van Leeuwen CMC, Post MWM. Psychosocial issues in spinal cord injury: a review. Spinal Cord 2012;50(5):382.

[24] Erosa NA, Berry JW, Elliott TR, Underhill AT, Fine PR. Predicting quality of life 5 years after medical discharge for traumatic spinal cord injury. British Journal of Health Psychology 2014;19(4):688-700.

[25] Khazaeipour Z, Norouzi-Javidan A, Kaveh M, Khanzadeh Mehrabani F, Kazazi E, Emami-Razavi SH. Psychosocial outcomes following spinal cord injury in Iran. The journal of Spinal Cord Medicine 2014;37(3):338-345.

How to cite this article: Ates E, Bilgili N. Effect of Web-Based Training on Complication Control and Quality of Life of Spinal Cord Damaged Individuals: Randomized Controlled Trial. Clin Exp Health Sci 2021; 11: 220-227DOI :10.33808/ clinexphealthsci.707654 